\title{
Lucanus zhuxiangi sp. n., a New Species from Southeast China (Coleoptera: Lucanidae: Lucaninae)
}

\author{
Cheng-Bin Wang ${ }^{1}$, Bi-Sheng Zhan ${ }^{2}$ \\ ${ }^{I}$ Innovation College, Mianyang Normal University, 166 Mianxing West Road, Mianyang, Sichuan Province, P. \\ R. China \\ ${ }^{2}$ School of Computer Science and Communication Engineering, Jiangsu University, Zhenjiang, Jiangsu \\ Province, P. R. China
}

*Corresponding Author: Cheng-Bin Wang, Innovation College, Mianyang Normal University, 166 Mianxing West Road, Mianyang, Sichuan Province, P. R. China

\begin{abstract}
A new species of stag beetle is described from Hunan and Guangdong, China, Lucanus zhuxiangi sp. n. (Coleoptera: Lucanidae: Lucaninae). Important morphological characters of the new species are illustrated by color plates.
\end{abstract}

Keywords: China, Lucanidae, Lucaninae, Lucanus, new species, taxonomy

\section{INTRODUCTION}

Lucanus Scopoli, 1763 is the type genus of Lucanidae (Coleoptera) with members distributed in Nearctic, Oriental and Palearctic Regions. However, the genus has the highest diversity in eastern Asia and many species are difficult to identified because of similar habitus. For the fauna of China, Huang \& Chen $(2010,2013,2017)$ excellently revised the Chinese species of Lucanus in their three milestone books, Stag beetles of China. And later Wang \& Zhu (2017) described L. zhanbishengi from Hunan, central China.

Huang \& Chen (2017) identified two male specimens from Nanling, North Guangdong as Lucanus brivioi ssp. incert. In the present paper, we describe and illustrate it as a new species L. zhuxiangi sp. n., basing on a large series of male and female specimens from Hunan and Guangdong, southeast China. Its diagnosis from congener species is provided. And the new species is compared with its most similar species L. brivioi Zilioli, 2003, on some selected but important morphological characters which are illustrated with color plates.

\section{MATERIALS AND METHODS}

Specimens were relaxed and softened in hot water for 24 hours, and then transferred to distilled water to clean, dissect and observe. In order to examine the genitalia of both sexes, the last two abdominal segments were detached and treated with $10 \%$ solution of potassium hydroxide for 12 hours and then preserved in $75 \%$ ethanol. After examination, the body parts were mounted on a glass slide with Euparal Mounting Medium for future studies. Habitus photographs were taken using a Canon macro photo lens EF-S 60mm on a Canon 5DsR. Photographs of morphological details were taken using a Zeiss Axio Zoom.V16 motorized stereo zoom microscope with a Zeiss AxioCam MRc 5. The final deep focus images were created with Zerene Stacker 1.04 stacking software. Adobe Photoshop CS6 was used for post-processing. The morphological terminology follows Huang \& Chen $(2010,2013$, 2017).

The material examined for this study is deposited in the following collections:

CAU China Agricultural University, Beijing, China

CBSZ Collection of Bi-Sheng Zhan, Zhenjiang, China 
Synthesis, Lucanus zhuxiangi sp. n., a New Species from Southeast China (Coleoptera: Lucanidae: Lucaninae)

CCZC Collection of Chao Zhou, Chengdu, China

CXZB Collection of Xiang Zhu, Beijing, China

Measurement criteria in millimetres ( $\mathrm{mm})$ are used as follows:

Body length: length between the apex of mandible to the elytral apex along the midline.

Elytral length: length between the basal border and the apex of elytra along suture.

Elytral width: widest part of both elytra combined.

Head length: length between the anterior apex of clypeus and the posterior margin of occiput along the midline.

Head width: widest part of head.

Mandible length: length from the apex of mandible to its base at anterior margin of the head.

Pronotal length: length of the pronotum along the midline.

Pronotal width: widest part of pronotum.

\section{RESUltS}

\section{Genus Lucanus Scopoli, 1763}

Vernacular name: 深山锹甲属

\section{Lucanus zhuxiangi sp. $\mathrm{n}$.}

http://zoobank.org/89E68A3E-8DA3-4C52-BA96-E0393AD71CE1

Vernacular name: 朱氏深山锹甲

Figs 1A-B, D-E; 2; 3A; 4; 5A-C, G; 6A-B; 7

Material Examined. Holotype: ${ }^{\lambda}$, CHINA, Hunan: Chenzhou City, Yizhang County, Mangshan Nature Reserve [莽山自然保护区], VI.2017, Xiang Zhu leg. (CAU). Paratypes: $7 ð ð 7 q$, , same data as holotype except: Xiang Zhu \& Bi-Sheng Zhan legg. (CXZB); $6 \hat{\jmath} 80$ + holotype except: VI.2016 (CXZB); 21§ð22우으, Guangdong: Nanling Nature Reserve [南岭自然保护区], VI.2014, Xiang Zhu leg. (CXZB); 40Љð28우, same data as previous except:

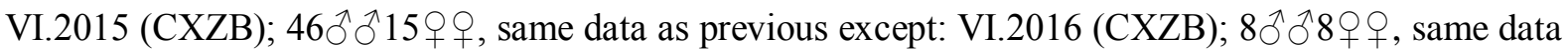
as previous except: VI.2017, Xiang Zhu \& Bi-Sheng Zhan legg. (CXZB). 1 $\delta^{\Uparrow}$, same data as previous except: 2.VII.2018, Huan Liu leg. (CCZC); + , same data as previous except: 11.VII.2018 (CCZC).

Diagnosis. Male: All tibiae and femora (Figs 1A-B) with yellowish stripes on dorsal and ventral surfaces; labrum slenderly subtriangular; anterior ridge of head subroundly elevated; lateral ridges of head (Fig 3A) broad, forming widely-rounded angles at lateral corners; major inner tooth (Fig 3A) preceded by 3-5 smaller teeth and followed by 8-10 smaller teeth that are not continued to the base of mandible; protibia (Figs 1A; 2A-B) with 4-5 large teeth along outer margin, some smaller or indistinct teeth of different sizes between large ones; 8th abdominal tergite (Fig 4A) with poorlydefined lateral angles; 8th abdominal ventrite (Fig 4B) without membranous area; ventral plate (Fig 4C) of 9th abdominal segment with linear longitudinal membranous stripe along midline of apical expansion; aedeagus with ventral plate (Fig 5A) at apical end of basal piece long, well sclerotized, widely emarginate at apical margin; paramere (Fig 5C) weakly upcurved at apex; penis (Fig 5A) long and slender, nearly as long as parameres; flagellum (Figs 5A-C) about 1.4 times as long as parameres, apex (Fig 5G) weakly enlarged. Female: all femora (Fig 1E) with yellowish stripes on ventral surfaces; pronotum (Fig 1D) widest at basal 2/5; elytra clothed with fine pubescence; protibiae (Fig 1D) with apical branches relatively broader and blunter; 8th abdominal tergite (Fig 4E) with poorlydefined lateral angles; 8th abdominal ventrite (Fig 4F) distinctly emarginate at middle of posterior 
margin; hemisternite (Fig 6A) moderately wide and inner lateral margin of sclerotized part long; spermatheca (Figs 6A, C) with proximal part moderately to strongly curved inwards, and weakly turned ventrad (Fig 6B); spermathecal duct (Fig 6A) about 2.1 times as long as spermatheca; spermathecal gland (Fig 6A) vermiform, shorter than spermatheca.

Description. Male Holotype. Large size, body $56.2 \mathrm{~mm}$ long. Length $(\mathrm{mm})$ of different body parts: head (7.7), mandible (22.7), pronotum (6.8), elytra (20.9); width (mm): head (16.4), pronotum (11.9), elytra (14.1).

Habitus (Figs 1A-B; 2B): Color mostly reddish brown to blackish brown on both dorsal and ventral surfaces; elytra sheen, reddish brown; all tibiae and femora with large, transverse, yellowish stripes on dorsal and ventral surfaces. Body clothed with fine, recumbent, yellowish pubescence, not longer and denser on metasternum.

Head (Fig 3A). Form transverse. Anterior ridge clearly defined and subroundly elevated. Lateral ridges broad, moderately protruded, forming widely-rounded angles at lateral corners. Clypeolabrum fused with frons, not defined by transverse suture, about 1.5 times as long as wide; labrum slenderly subtriangular, with dorsal branch, subrounded at apex. Mandible about 3.0 times as long as head, distinctly incurved at basal $1 / 3$, then straight to apex; apical fork with upper branch markedly longer than lower branch; major inner tooth slender and longer than width of mandible; major inner tooth preceded by 3-5 smaller teeth and followed by 8-10 smaller teeth that are not continued to the base of mandible. Antennal club with 4 antennomeres; antennomere VII slender and sharply pointed apically; antennomeres VIII-X lamellate.

Legs (Figs 1A; 2B). Protibia with 4-5 large teeth along outer margin, some smaller or indistinct teeth of different sizes between large ones; apex bifurcate with branches bluntly rounded at tip. Except apical spurs and spines, mesotibia with 4 or 5 small lateral spines (basal one or two tiny) and metatibia with 3 spines (basal one tiny).

Male genitalia. 8th abdominal tergite (Fig 4A) with poorly-defined lateral angles. 8th abdominal ventrite (Fig 4B) without membranous area and weakly protruded at middle of posterior margin. Ventral plate (Fig 4C) of 9th abdominal segmentwith linear longitudinal membranous stripe along midline of apical expansion. Aedeagus (Fig 5A) in dorsal view about 2.6 times as long as wide. Basal piece (Fig 5A) in dorsal view oblong, nearly 1.6 times as long as parameres, with pair of sclerotized dorsal plates (Fig 5B); ventral plate (Fig 5A) at apical end of basal piece long, well sclerotized, widely emarginate at apical margin. Paramere with wide basal process (Fig 5B); apex weakly upcurved (Fig 5C). Penis (Fig 5A) long and slender, nearly as long as parameres. Flagellum (Figs 5A-C) relatively short, about 1.4 times as long as parameres, apex (Fig 5G) weakly enlarged.

Male Paratypes. Body 41.0-63.9 mm long (Figs 2A-D).

Variation. In large-sized males, apical fork of mandible more opened, number of inner teeth more, clypeolabrum longer, anterior ridge of head well elevated; while in small-sized males, apical fork of mandible less opened, number of inner teeth fewer, clypeolabrum shorter, anterior ridge of head weakly elevated.

Female Paratype. Body $32.0 \mathrm{~mm}$ long. Length (mm) of different body parts: head (4.2), mandible (3.5), pronotum (6.7), elytra (17.7); width (mm): head (8.3), pronotum (10.7), elytra (12.0).

Habitus (Figs. 1D-E). Color mostly black on both dorsal and ventral surfaces; ventral surface of profemora, dorsal and ventral surfaces of meso- and metafemora with transverse yellowish stripes. Body clothed with fine, recumbent, yellowish pubescence, not longer and denser on metasternum.

Head (Fig. 1D). Canthus with both anterior and posterior angles clearly defined; anterior angle inside of eye; lateral margin weakly concave. Anterior and lateral ridges absent. Clypeolabrum transverse, weakly emarginate at apex. Right mandible with low dorsal tooth, inner tooth with broad and flat inner ridge; left mandible without dorsal tooth, with 2 widely-separated inner teeth and small gap behind apex, inner margin between teeth long, weakly concave. 
Pronotum (Fig. 1D). Form 1.6 times as wide as long, widest at basal 2/5; anterior angle rounded; lateral angles weakly defined; posterior angle widely subrounded.

Legs (Fig. 1D). Protibia with 3 distinct teeth along outer margin; apex bifurcate, with branches relatively broader, blunter, and basal branch much more expanded.

Female genitalia. 8th abdominal tergite (Fig 4E) with poorly-defined lateral angles. 8th abdominal ventrite (Fig 4F) with a membranous area in the middle and distinctly emarginate at middle of posterior margin. Hemisternite (Fig 6A) moderately wide, broadly rounded apically, with outer apex not produced beyond inner apex; inner lateral margin of sclerotized part long. Spermatheca (Figs 6A, C) sclerotized, J-shaped; proximal part moderately to strongly curved inwards, and weakly turned ventrad (Fig 6B). Spermathecal duct (Fig 6A) long, about 2.1 times as long as spermatheca. Spermathecal gland (Fig 6A) vermiform, shorter than spermatheca. Central conjunction of 9th tergite protruding medially and roundly narrowed at tip.

Field Observations. Mating behavior of Lucanus zhuxiangi sp. n. in Mangshan Nature Reserve (Hunan) as shown in Figs 7A-C.

Etymology. The specific epithet is dedicated to Mr. Xiang Zhu (Beijing, China), one of the collectors of this new species and an enthusiastic amateur entomologist. The name is a noun in the genitive case.

Distribution. China (Guangdong, Hunan).

Remarks. This new species should be assigned to the Lucanus fortunei group (sensu Huang \& Chen 2010). It well resembles L. brivioi Zilioli, 2003 in general appearance (their aedeagi also similar to each other, however, there are still differences on the curvatures of the outer margins of penis and the size of the apices of flagellum), but it can be distinguished by the combination of the following characters: in L. zhuxiangi sp. n., male: all tibiae and femora (Figs 1A-B) with yellowish stripes on dorsal and ventral surfaces, labrum more slender, major inner teeth (Fig 3A) of mandibles stouter, lateral ridges (Fig 3A) of head round at lateral corners, ventral plate (Fig 4C) of 9th abdominal segment with linear longitudinal membranous stripe along midline of apical expansion; female: all femora (Fig 1E) with yellowish stripes on ventral surfaces, protibiae (Fig 1D) with apical branches relatively broader and blunter, 8th abdominal ventrite (Fig 4F) distinctly emarginate at middle of posterior margin, hemisternite (Fig 6A) moderately wide and inner lateral margin of sclerotized part long, spermatheca (Figs 6A, C) with proximal part moderately to strongly curved inwards.

While in L. brivioi Zilioli, male: all tibiae and femora (Fig 1C) with reddish stripes on dorsal and ventral surfaces, labrum shorter, major inner teeth (Fig 3B) of mandibles more slender, lateral ridges (Fig 3B) of head obtuse at lateral corners, ventral plate of 9th abdominal segment only with small membranous area at the median of apical part; female: all femora (Fig 1F) almost uniformly black, protibiae (Fig 1F) with apical branches relatively smaller and sharper, 8th abdominal ventrite weakly emarginate at middle of posterior margin, hemisternite (Fig 6D) rather wide and inner lateral margin of sclerotized part short, spermatheca (Fig 6D) with proximal part straight or weakly curved inwards.

Lucanus zhuxiangi sp. n. is also somewhat similar to L. deuveianus Boucher, 1998 and L. hewenjiae Huang \& Chen, 2013 from Guangxi Province, but it is not difficult to distinguish it from them by the combination of characters in the above paragraph of Diagnosis.

\section{Lucanus brivioi Zilioli, 2003}

Vernacular name: 布氏深山锹甲

Figs 1C, F; 3B; 5D-F, H; 6C-D

Material Examined. $3 \hat{\jmath} 1$, , CHINA, Fujian: Quanzhou City, Dehua County, Daiyunshan Nature Reserve, 1500 m, VI.2016, Bi-Sheng Zhan leg. (CBSZ).

Distribution. China (Fujian). 


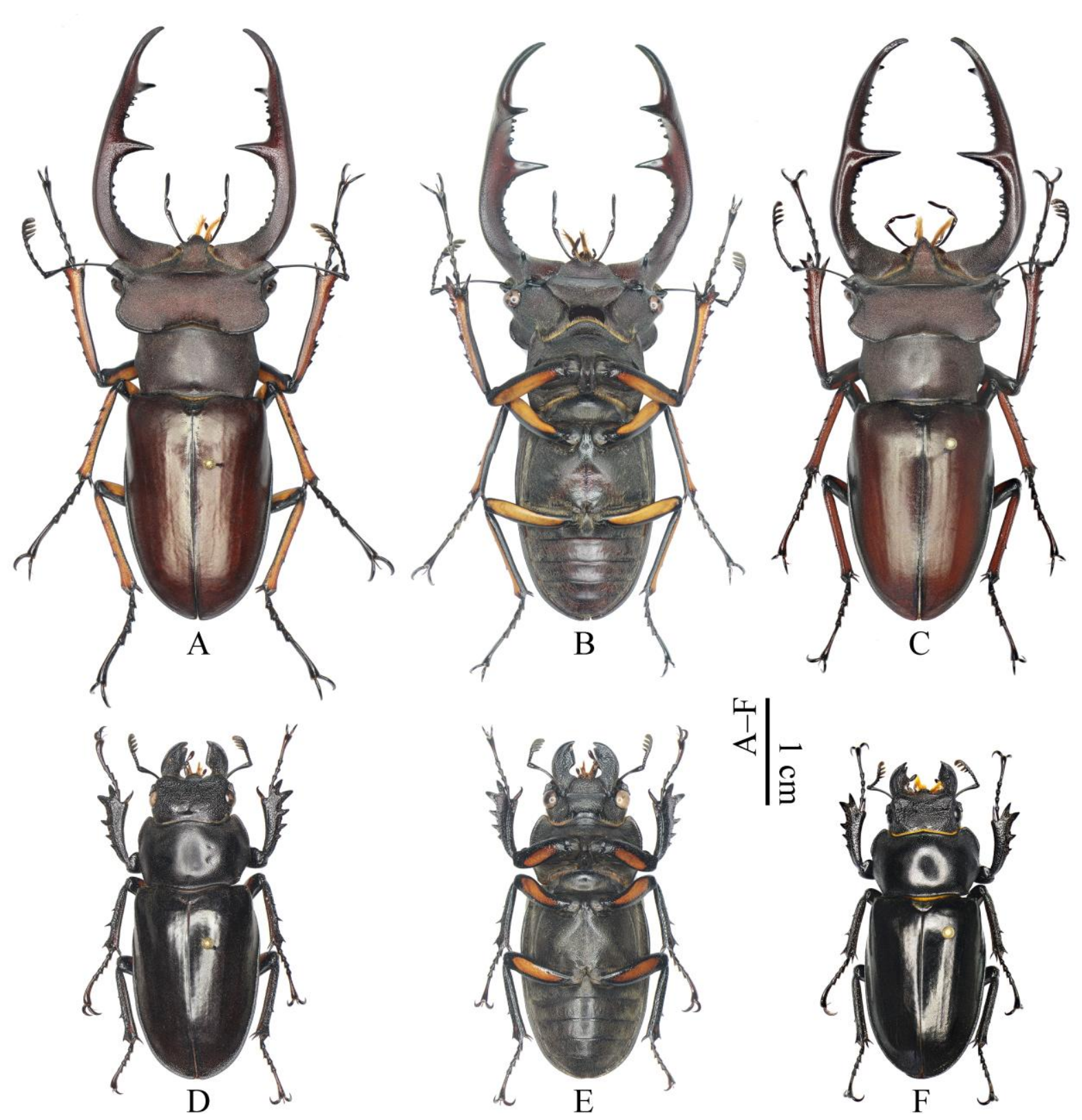

Figure 1. Habitus of Lucanus spp. $\boldsymbol{A}-\boldsymbol{B}, \boldsymbol{D}-\boldsymbol{E}$ L. zhuxiangi sp. n., Hunan $\boldsymbol{A}-\boldsymbol{B}$ holotype, ${ }^{\uparrow} \boldsymbol{D}-\boldsymbol{E}$ paratype, $, \boldsymbol{C}, \boldsymbol{F}$ L. brivioi Zilioli, 2003, Fujian $\boldsymbol{C}$ ô $\boldsymbol{F}$. $. \boldsymbol{A}, \boldsymbol{C}, \boldsymbol{D}, \boldsymbol{F}$ dorsal view $\boldsymbol{B}, \boldsymbol{E}$ ventral view. 


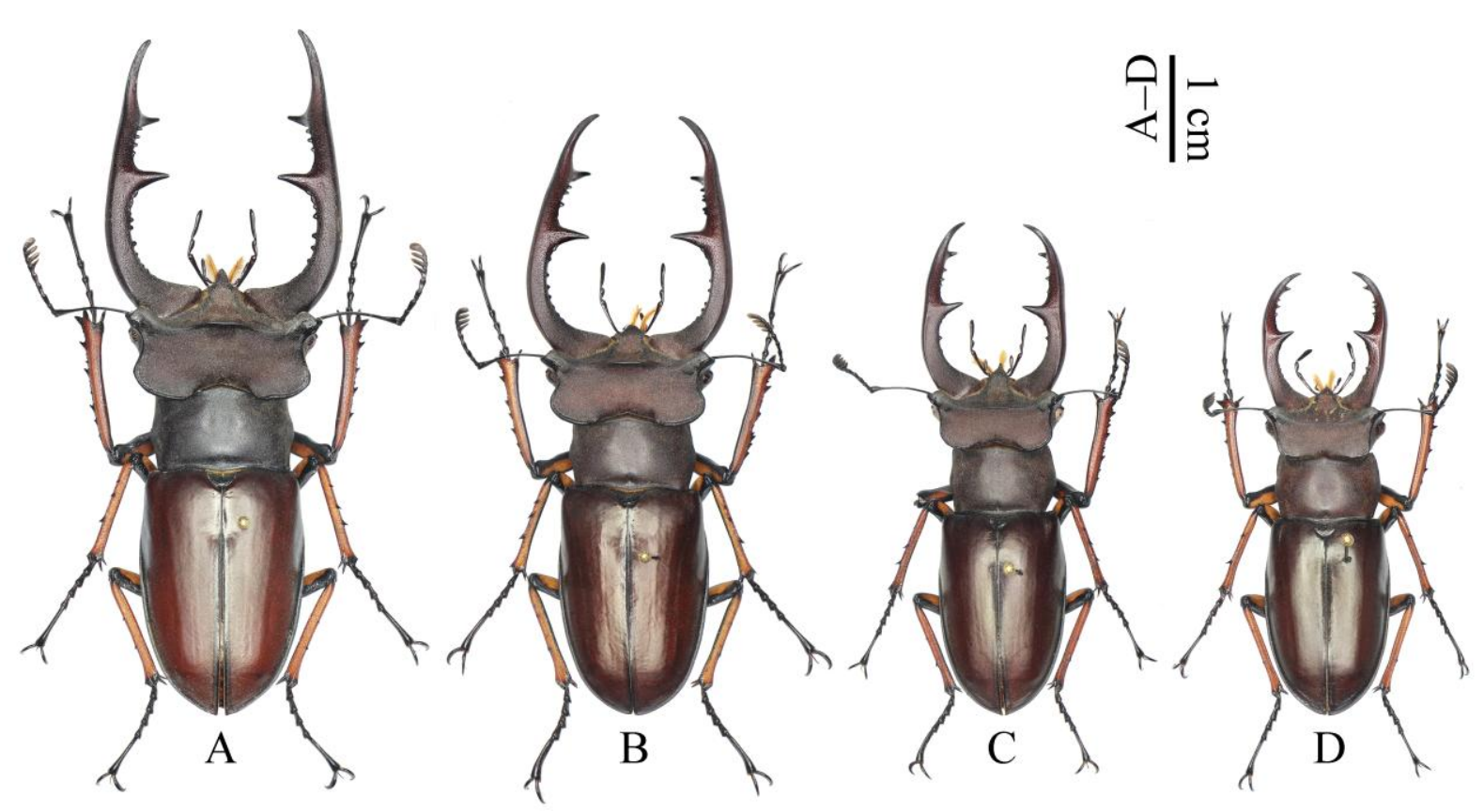

Figure 2. Habitus of Lucanus zhuxiangi sp. n., ồ $\hat{\jmath}$, Hunan, dorsal view. A paratype, large-sized $\boldsymbol{B}$ holotype, common-sized $\boldsymbol{C}$ paratype, moderate-sized $\boldsymbol{D}$ paratype, small-sized.
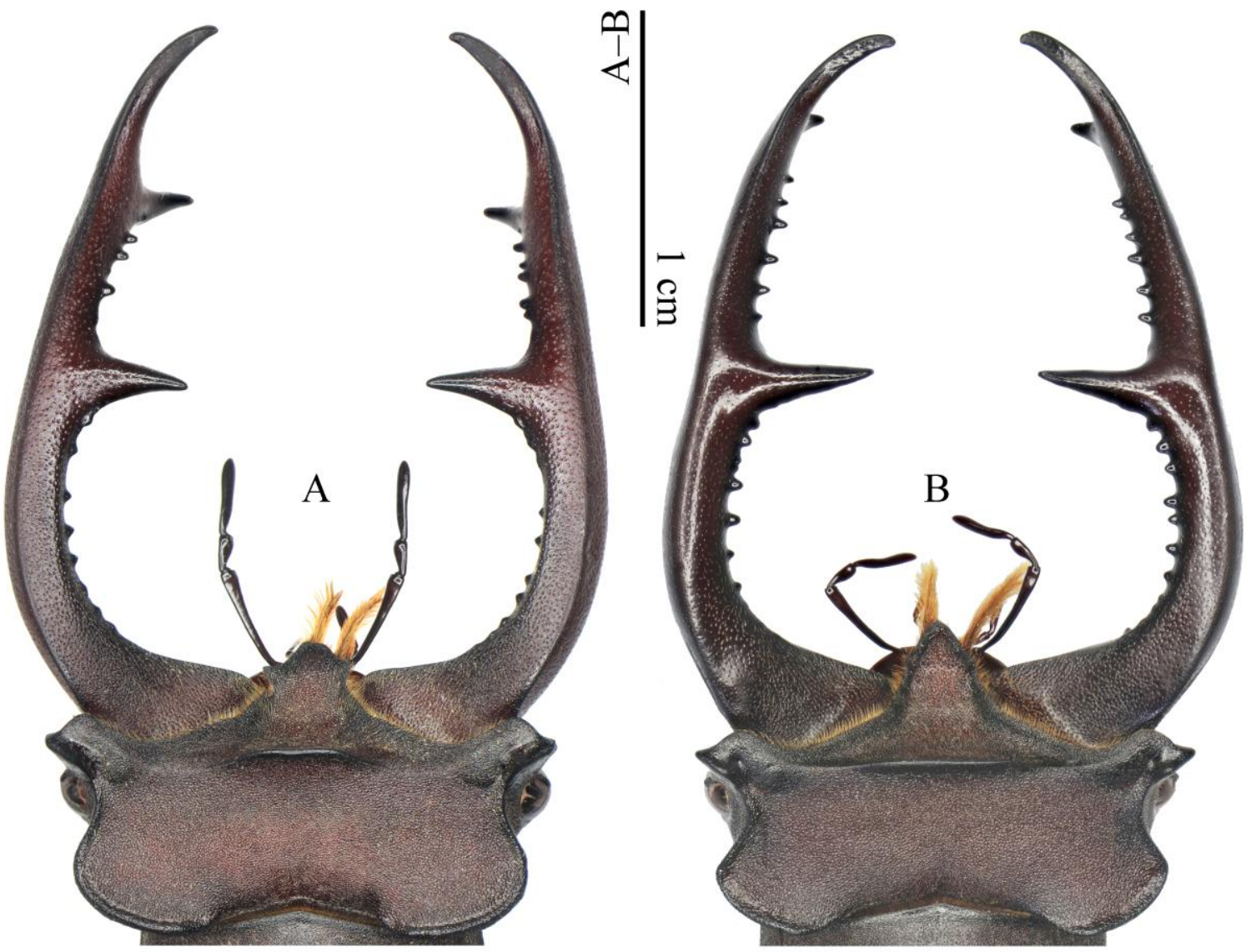

Figure 3. Heads of Lucanus spp., $\widehat{O}^{\widehat{\partial}}$, dorsal view. A L. zhuxiangi sp. n., holotype, Hunan B L. brivioi Zilioli, 2003, Fujian. 
Synthesis, Lucanus zhuxiangi sp. n., a New Species from Southeast China (Coleoptera: Lucanidae: Lucaninae)
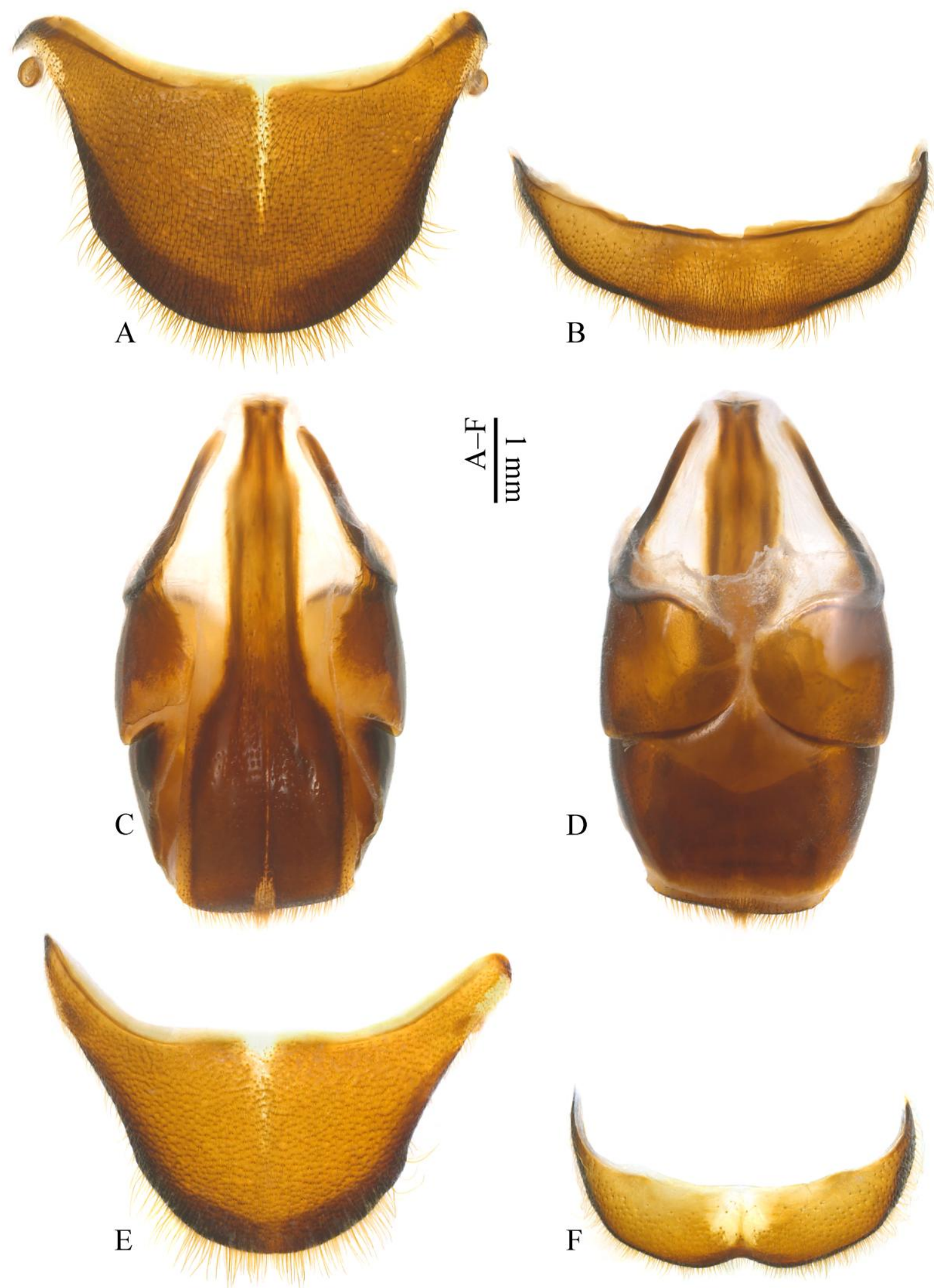

Figure 4. Lucanus zhuxiangi sp. n., Hunan. $\boldsymbol{A}-\boldsymbol{D}$ holotype, $\widehat{\jmath} \boldsymbol{A}$ 8th abdominal tergite $\boldsymbol{B}$ 8th abdominal ventrite $\boldsymbol{C}-\boldsymbol{D}$ 9th abdominal segment $\boldsymbol{E}-\boldsymbol{F}$ paratype, $q \boldsymbol{E}$ 8th abdominal tergite $\boldsymbol{F}$ 8th abdominal ventrite. $\boldsymbol{A}, \boldsymbol{D}, \boldsymbol{E}$ dorsalview $\boldsymbol{B}, \boldsymbol{C}, \boldsymbol{F}$ ventral view. 
Synthesis, Lucanus zhuxiangi sp. n., a New Species from Southeast China (Coleoptera: Lucanidae: Lucaninae)

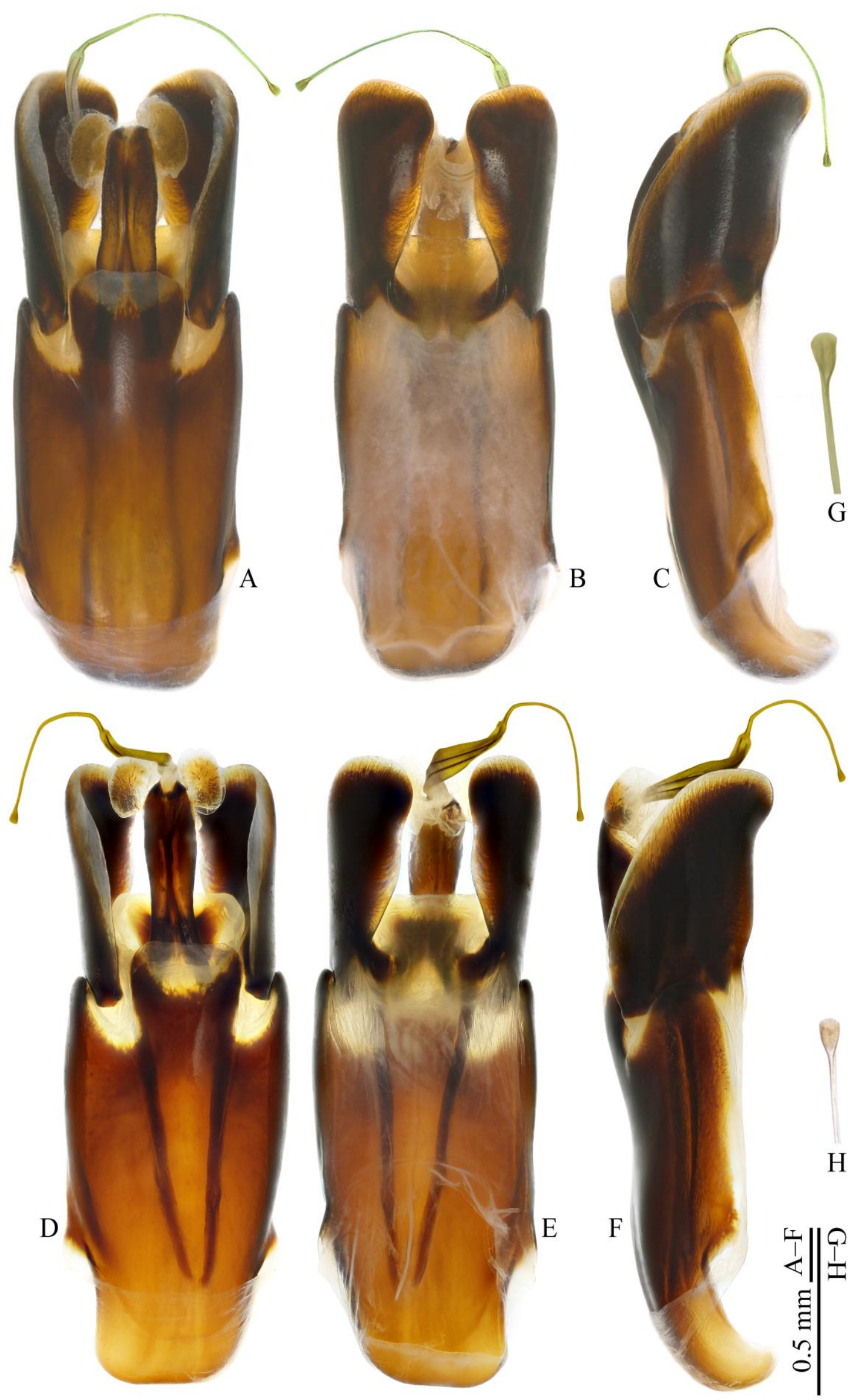

Figure 5. Aedeagi of Lucanus spp. (G-H apices of flagellum). $\boldsymbol{A}-\boldsymbol{C}, \boldsymbol{G}$ L. zhuxiangi sp. n., holotype, Hunan $\boldsymbol{D}-$ $\boldsymbol{F}, \boldsymbol{H}$ L. brivioi Zilioli, 2003, Fujian. A, D ventral view B, E, G, $\boldsymbol{H}$ dorsal view $\boldsymbol{C}, \boldsymbol{F}$ lateral view. 
Synthesis, Lucanus zhuxiangi sp. n., a New Species from Southeast China (Coleoptera: Lucanidae: Lucaninae)

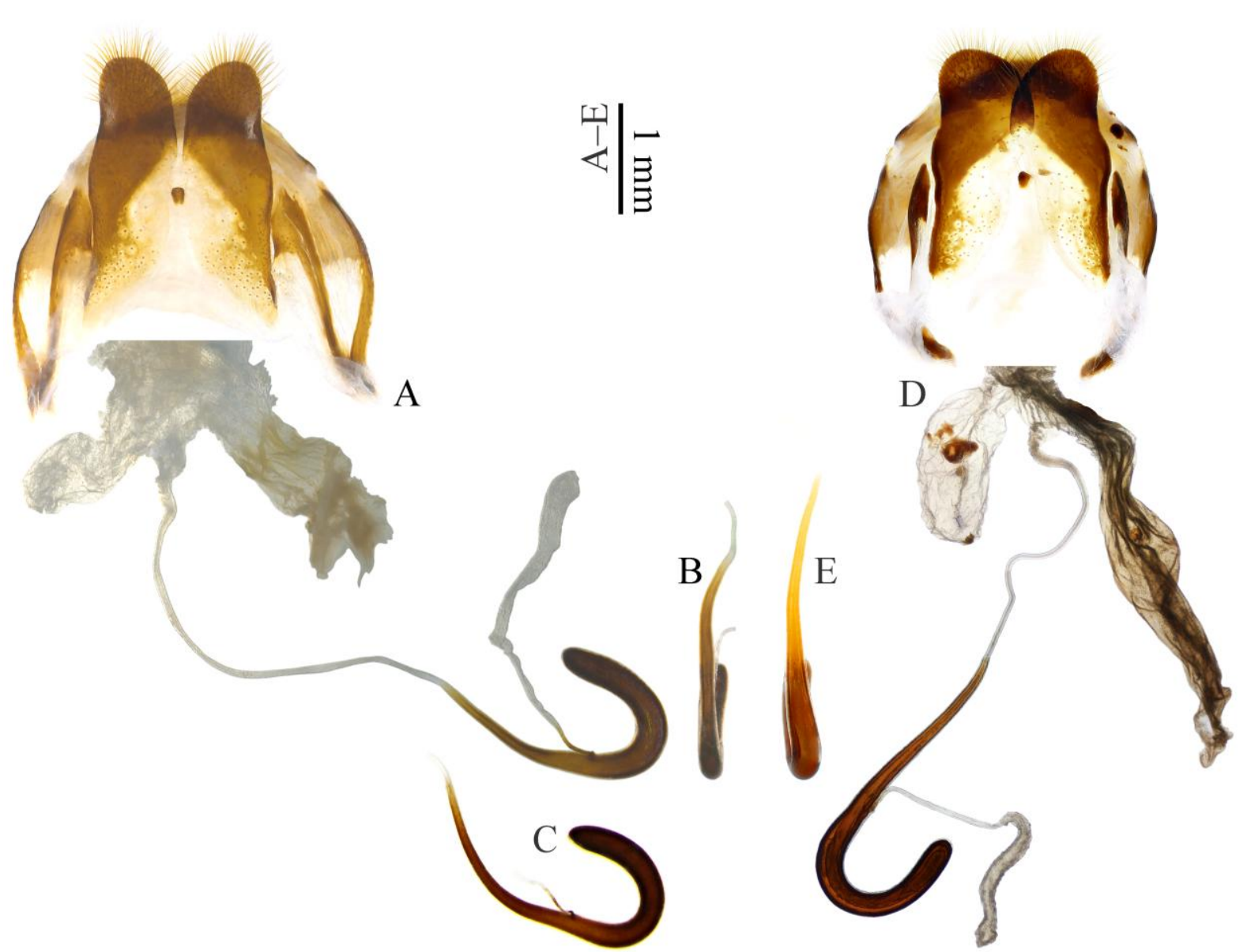

Figure 6. Female genitalia of Lucanus spp. A-C L. zhuxiangi sp. n., paratype, Hunan $\boldsymbol{D}-\boldsymbol{E}$ L. brivioi Zilioli, 2003, Fujian. A, $\boldsymbol{C}, \boldsymbol{D}$ ventral view $\boldsymbol{B}, \boldsymbol{E}$ right lateral view of spermathecae. 
Synthesis, Lucanus zhuxiangi sp. n., a New Species from Southeast China (Coleoptera: Lucanidae: Lucaninae)
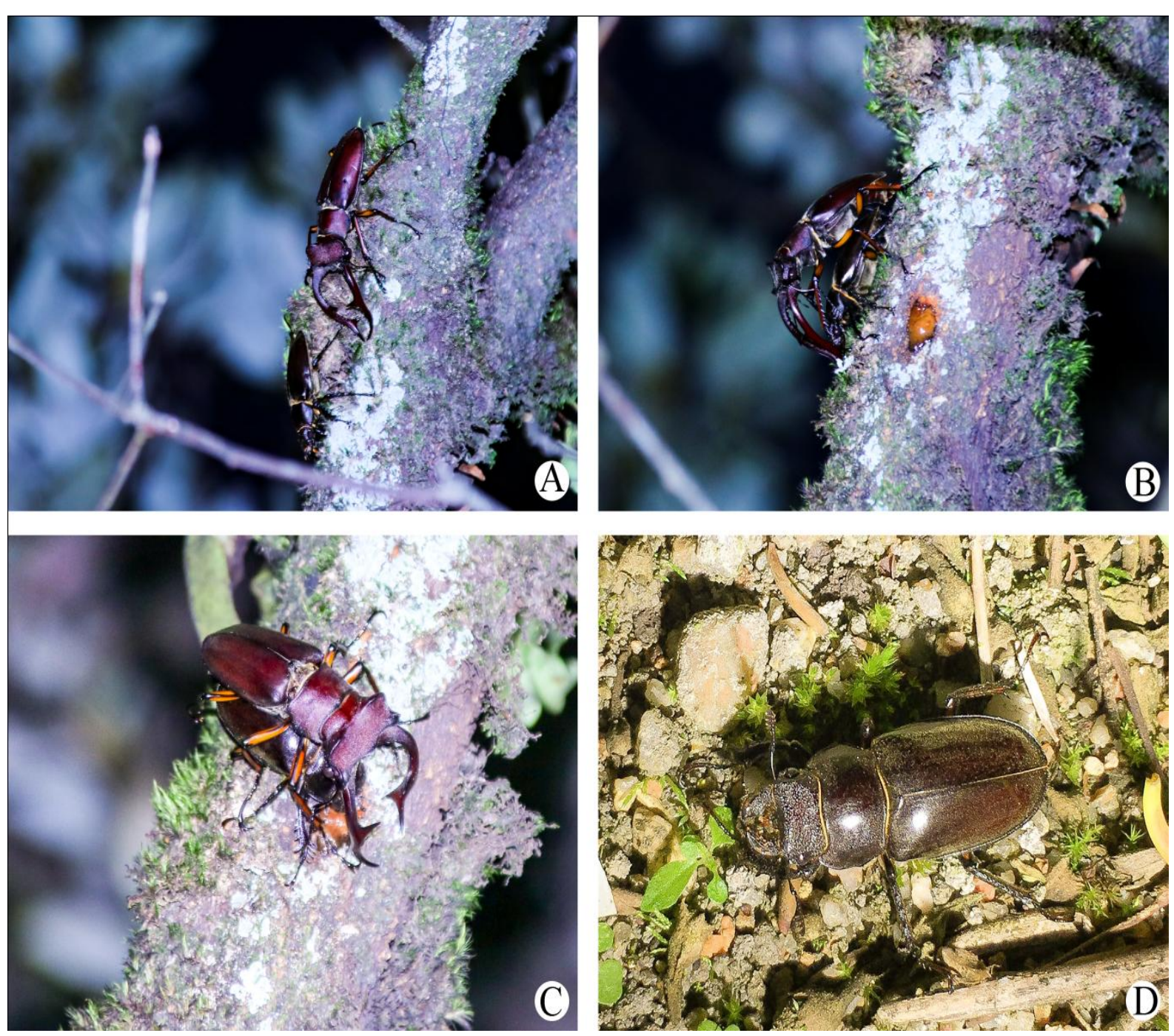

Figure 7. Field observations (Hunan: Mangshan Nature Reserve) of Lucanus zhuxiangi sp. $n$. (A-C photoed by Jun Chen $\boldsymbol{D}$ photoed by Xiang Zhu) $\boldsymbol{A}$ approaching $\boldsymbol{B}-\boldsymbol{C}$ mating $\boldsymbol{D}$ female on the ground.

\section{ACKNOWLEDGEMENTS}

We would like to express our sincere gratitude to Xiang Zhu (Beijing, China) for providing most specimens of the new species. We are obliged to the staffs of Mangshan Nature Reserve and Nanling Nature Reserve for their field support, especially thanks Jun Chen (Mangshan Nature Reserve, Chenzhou, China) for taking mating photographs of the new species. Our appreciation is due also to Chang-Chin Chen (Tianjin, China), Wen-I Chou (Taitung, China), Li He (Chengdu, China), Liang He (Institute of Zoology, Chinese Academy of Sciences, Beijing, China), Bin Liu (Bin Insect Taxonomy Studio, Beijing, China), Liang Lü (Hebei Normal University, Shijiazhuang, China), Lu Qiu (Southwest University, Chongqing, China), Jan Růžička (Czech University of Life Sciences, Prague, Czech Republic), Hao Xu (Hunan Agricultural University, Changsha, China), Xia Wan (Anhui University, Hefei, China), Qiao-Zhi Yang (Beijing, China), Chao Zhou (Chengdu, China), HongZhang Zhou (Institute of Zoology, Chinese Academy of Sciences, Beijing, China) for their considerable help in our study. We are grateful to Bin Liu, Chao Zhou and Xiang Zhu, reviewers who provided constructive comments on previous versions of the manuscript. This study was supported by the Bin Insect Taxonomy Studio (No. 2018).

\section{REFERENCES}

[1] Huang H, Chen C-C (2010) Stag beetles of China I. Formosa Ecological Company, Taipei, 288 pp.

[2] Huang H, Chen C-C (2013) Stag beetles of China II. Formosa Ecological Company, Taipei, 716 pp.

[3] Huang H, Chen C-C (2017) Stag beetles of China III. Formosa Ecological Company, Taipei, 524 pp. 
Synthesis, Lucanus zhuxiangi sp. n., a New Species from Southeast China (Coleoptera: Lucanidae: Lucaninae)

[4] Wang C-B, Zhu X (2017) Lucanus zhanbishengi sp. n., a new species from Hunan, central China (Coleoptera: Lucanidae: Lucaninae). International Journal of Research Studies in Zoology 3(4): 54-69. http://dx.doi.org/10.20431/2454-941X.0304008

[5] Zilioli M (2003) Lucanus brivioi n. sp., a new stag-beetle from the Wuyi shan mountains, Fujian, China (Coleoptera Lucanidae). Atti della Società Italiana di Scienze Naturali e del Museo Civico di Storia Naturale di Milano 144: 265-272.

Citation: Cheng-Bin Wang, Bi-Sheng Zhan "Synthesis, Lucanus zhuxiangi sp. n., a New Species from Southeast China (Coleoptera: Lucanidae: Lucaninae)", International Journal of Research Studies in Zoology, vol. 4, no. 3, p. 1-11, 2018. http://dx.doi.org/ 10.20431/2454-941X.0403001

Copyright: (c) 2018 Authors. This is an open-access article distributed under the terms of the Creative Commons Attribution License, which permits unrestricted use, distribution, and reproduction in any medium, provided the original author and source are credited. 